\title{
ENSAIO SOBRE A LOUCURA
}

\author{
Essay About Madness
}

\author{
Carla Regina Françoia ${ }^{1}$
}

\section{Resumo}

Esse ensaio tem como objetivo apresentar uma breve passagem sobre as várias formas de entendimento da loucura, desde seus eventos na Antiguidade, sua visada trágica, seus aspectos demoníacos até chegar no que hoje se traduz por uma compreensão orgânica do estatuto do mental. Ao final desta trajetória, incluir o entendimento de Jacques Lacan no que se refere à possibilidade da constituição humana e sua relação com o evento da loucura. Esta, na teoria desse autor, passa a ser vista como o sentido que o homem pode dar ao mundo que o cerca e, também, como uma expressão exagerada daquilo que compõe a gênese do eu no homem, a saber: a identificação a uma imagem que, a princípio, o aliena e, depois, o constitui. A conclusão deste ensaio será apresentada pelo viés da atual concepção de loucura e como isto interfere na possível reforma psiquiátrica que o sistema de saúde brasileiro quer promover.

Palavras-chave: Loucura, Lacan, psiquiatria, gênese do eu, história.

\section{Abstract}

This essay intends to present a short passage about all of the ways of the understanding of madness, since its events on the ancient times, its tragic sought, its demonic aspects until its evolution to what, nowadays, can be understood as an organic comprehension of mental statute. In the end of this trajectory, its intended to include Jacques Lacan's understandings, which are related to human constitution's possibility and its connexion with the event of madness. This, in its author's theory, becomes to be seen as the explanation men can give to the world around him, and also, as an exaggerated expression of what composes the "me" genesis in the men: the identification of a image that first makes him alienated and after, gives him a support. The conclusion of this essay will be presented by the oblique directions of actual conception of madness and how it interferes in the possible psychiatry reform that Brazilian's Heath System intends to provide.

Keywords: Madness, Lacan,psychiatry, me genesis, history.

1 Psicanalista, Especialista em Filosofia pela UFPR; Mestranda em Filosofia pela UFPR. Endereço para contato: R: Senador Xavier da Silva, 488 cj. 204 - Centro Cívico - Curitiba-PR. CEP 80530-060.

E-mail: carrefran@hotmail.com 
Muito se discute, nos dias de hoje, com a reforma do sistema psiquiátrico, o que fazer com pacientes que estão encerrados nestes espaços, anteriormente denominados asilos, pois não haverá, fechando tais hospitais, onde confiar o louco e a sua loucura. É impressionante o rechaço que o homem sofre, desde outros tempos, caso seja portador de síndromes, transtornos, manias, depressão, entre outras formas da manifestação louca, que transforma toda a estética da vida num horror para quem olha e, por isso, precisa ser tirado do alcance do olhar. Houve, no entanto, um momento em que a loucura era desígnio divino, efeito demoníaco ou obra de arte e cada uma destas formas de explicá-la traz consigo uma época diferente, mas a mesma característica no que concerne à resistência em relação a aceitação do homem louco. É o que privilegia este ensaio: menos um levantamento histórico e mais um apontamento deveras humilde, pois se trata de um ensaio e isto já trás, em si, seus limites - da posição em que se encerrava o louco nas diferentes épocas e, a posteriori, como a atualidade lida com esse efeito de causas tantas vezes já discutidas. Com efeito, será trabalhado, mais pormenorizadamente, um artigo de Jacques Lacan que apresenta, exclusivamente, uma forma outra de compreensão da loucura isso não quer dizer que a psicanálise lacaniana será tratada no presente ensaio, apenas esse artigo citado que guiará nosso entendimento atual da loucura.

Na Antiguidade a loucura era vista, no comportamento humano, devido a uma vontade dos deuses, todavia, esse período governado pelo Olimpo apresentava uma contradição no que se refere ao homem e a sua obediência ao divino. Pois, as vontades divinas interferiam nas atitudes humanas na mesma proporção em que o homem assumia a responsabilidade pelo descontrole emocional. Segundo Pessotti (1995), os deuses agiam “(...) decidindo soberana o curso das coisas e dos homens (...) forçando as 'iniciativas' humanas (...) Roubando dos homens a razão. A loucura seria, então, um recurso da divindade para que seus projetos ou caprichos não sejam contrastados pela vontade dos homens" (p. 14). O homem antigo pode ser compreendido por dois modos distintos e simultâneos: primeiro, os deuses tiravam-lhe a capacidade de compreensão, pois este homem não era dotado de autonomia no que se refere a seus afetos, decisões e, até mesmo, na condução do corpo, tudo era poder divino; segundo, o homem assumia a responsabilidade pelas suas ações, e, até, punia-se por elas, por mais que tivessem sido por interferência dos deuses. "Cada ato insensato é produto de uma atê causada, produzida por Zeus, derivada dele como uma filha" (Pessotti, 1995, p. 17). O comportamento louco tinha como etiologia a mitologia que explicava a influência das entidades divinas, ou outras entidades a serviço dos deuses, na causa dos eventos que levava ao delírio, suicídio, homicídio, transgressão das normas sociais entre outros comportamentos desajustados. Grosso modo, pode-se inferir que o homem aceitava seu desígnio, seu destino, afinal, era a vontade dos deuses e homem algum escapava desta fúria.

Seguindo o desenvolvimento dos fatos, houve uma importante alteração epistemológica em relação a esta concepção mitológica do louco. Os trágicos acrescentaram ao desígnio divino os conflitos passionais. Surge um modelo psicológico-passional, como afirma Pessotti (1995), de perceber o alienado. Isto quer dizer que o homem passou a ser visto como um ser que traz em si os eventos, furiosos ou medrosos, como resultado dos seus a petites. A vontade divina ainda atuava sobre a sorte do homem, mas a loucura como comportamento - como efeito de uma causa tal como ciúme, ódio, homicídio, entre outros - acontecia porque o homem passou a ser compreendido como um ser dotado de capacidades psicológicas. Já com as formulações de Hipócrates (460 - 377 a.C.) grande médico da Antiguidade, houve uma exclusão total da explicação mitológica da loucura e o louco passou a ser compreendido - por uma doutrina que terá influência durante muito tempo na compreensão da loucura - como portador de um desarranjo da sua natureza orgânica em conseqüência do desequilíbrio das forças das condições ambientais. Dessa forma, nasceu uma visão organicista da loucura que se tornou uma doença do cérebro, surgindo, com isso, um método clínico e nosográfico de tratar e caracterizar a loucura. Mas, essa visão organicista que visava a uma melhora da doença, transformou-se com o advento do cristianismo. O homem foi inserido num contexto que, segundo Pessotti (1995) "não há dois mundos em conflito, cada um é obra de um criador, o mau e o bom, o demônio e Deus" (p. 84). O louco era um homem que estava ou possuído pelo diabo ou sofrendo tormentos constantes por parte deste, causando, em conseqüência destas situações, delí- 
rios, mania, melancolia, obsessões, somatizações histéricas. Essa doutrina demológica da loucura é bem explicitada em uma obra intitulada Malleus Maleficarum escrita em 1484, baseada na Summa Theologica de Santo Agostinho e o Segundo Livro das Sentenças de Santo Tomás de Aquino e que era utilizada para ajudar os inquisidores a identificar casos de possessão. Na época moderna, com o surgimento da noção de consciência com Descartes, a loucura passa de um referencial demoníaco para um outro em que a razão e desrazão não podem ao mesmo tempo estar num mesmo lugar. A consciência passa a ser o lugar do homem e 0 pensamento determina sua existência. Quando, então, os eventos no homem começam a acontecer por ele mesmo nascem as ciências naturais. Isto é, os eventos externos não têm mais poder de causa sobre o homem, ele tem como referencial o seu eu que é um eu racional.

Pinel - em 1973 foi o mártir do acontecimento do grande internamento que retirou das ruas todos aqueles que tiravam as situações de uma ordem estabelecida - soltou as amarras dos sifilíticos, velhos, vagabundos e prostitutas, mas, em relação aos loucos, passou a observar seus comportamentos classificando-os dentro de uma visão nosográfica. Solto das amarras, o alienado passou a ser controlado pelo olhar e depois pelo discurso médico que fez nascer o saber psiquiátrico, uma mutação do que era conhecido como loucura à doença. Com essa passagem de um estatuto para outro, abriram-se vários questionamentos em relação à forma com que se lida com a doença mental e uma delas é: como a psiquiatria enquadra-se dentro de uma explicação organicista da doença, sendo seu objeto o mental? Canguilhem (2002) afirma que os fenômenos patológicos "nada mais são do que variações quantitativas, para mais ou para menos, dos fenômenos fisiológicos correspondentes" e, a psiquiatria adere a esse princípio quantitativo da doença, para garantir um lugar no campo da ciência, mais especificamente da ciência médica. Entretanto, pelo menos no que diz respeito a um objeto da psiquiatria, um dilema é trazido à baila: a relação corpo e mente. Pois, o objeto da psiquiatria é o estatuto mental, e para pertencer a uma ciência que respaldasse suas formulação em relação à loucura, colocou-se o corpo como substrato da doença mental, tirando completamente esse mental da sua posição de causa, sendo apenas um efeito de superfície. Surge, no entanto, uma saída para este impasse, que será um retorno à psicologia. Mas, novamente, um outro dilema se abre para a psiquiatria. Pelo fato da psicologia não oferecer uma base segura à psiquiatria - como, por exemplo, a fisiologia oferece a medicina - esta se torna uma aliada constante da medicina, aderindo a uma visão organogenética de doença e perdendo o mental que é o seu objeto. Assim, o psíquico fica defasado em relação ao corpo e a conseqüência desse evento para o diagnóstico das patologias psíquicas é posto que o fenômeno mental é uma resposta de uma disfunção orgânica.

Enfim, surge um psiquiatra de, por incrível que pareça, formação tradicional que em 1932 defendeu sua tese de doutoramento intitulada " $\mathrm{Da}$ psicose paranóia em suas relações com a personalidade", e em 1946, num congresso de psiquiatria organizado por Henri Ey - seu antigo colega de residência médica - para discutir sobre a psicogênese, afirma que não é a loucura uma disfunção neuronal, ou um déficit orgânico, mas sim, uma questão de sentido. O sentido que o homem dá ao seu mundo e para si mesmo. Lacan subverte a compreensão em pontos importantes no que tange à loucura, por estar ele em 1946, com um projeto de reformular a Psicologia para que esta pudesse respaldar tanto a Psiquiatria quanto a Medicina, ou melhor, um projeto de constituir uma ciência suficientemente concreta da subjetividade que, ao mesmo tempo, não tomasse a subjetividade como algo absoluto no homem - como rezava a psiquiatria fenomenológica de Jaspers - e descaracterizar a concepção organicista de doença mental, da psiquiatria clássica, trazendo, o sujeito, para dentro da loucura. Assim, essa nova vertente para a loucura, a de tirar o déficit neuronal e incluir 0 sujeito, transformará, mais uma vez, todo um modo de se compreender o homem. Vale ressaltar que nesse momento, Lacan ainda não estava atrelado à Psicanálise como uma teoria eleita para responder às questões humanas. Muito pelo contránio. Esse período da obra de Lacan é marcado por um certo repúdio pelo conceito de inconsciente - entre outras noções metapsicológicas - considerado como uma noção inerte e impensável. Por isso, a psicologia ainda era a ciência que Lacan tentava organizar, projeto este que teve como primeiro autor Politzer - um autor que não aceitava a forma com que a psicanálise lidava com suas noções metapsicológicas, isto é, o substancialismo de seus 
conceitos era inaceitável por Politzer, enquanto que a técnica da psicanálise não sofria tão árdua crítica por parte deste teórico da psicologia. Voltemos ao louco.

Em 28 de setembro de 1946, no Congresso de Bonneval, Lacan vai propor uma formalização radical do problema da causalidade psíquica num debate colocado por Henri Ey sobre a psicogênese. $\mathrm{O}$ nosso autor abre a reunião imediatamente criticando a teoria de Henri Ey, denunciando-a como "... incompleta e falsa, e que se designa a si mesma em psiquiatria pelo nome de organicismo" (Lacan, 1998, p.153). Essa concepção denominada de organo-dinamismo remete, na fala de Lacan, o distúrbio mental a um mau funcionamento do corpo. Essa crítica da concepção de Henri Ey, Lacan a faz para delimitar a fronteira entre eles e circunscrevê-la em oposição "as funções da idéia verdadeira” (Lacan, 1998, p.154). E mais adiante, Lacan continua: "a questão da verdade condiciona, em sua essência, o fenômeno da loucura e, ao se querer evitá-la, castra-se esse fenômeno de significação, por onde eu penso mostrar-lhes que ele se atém ao ser mesmo do homem" (Lacan, 1998, p.154). É preciso notar que tanto uma definição de homem e até mesmo da loucura entra num estatuto de sentido que é por onde Lacan demonstrará a sua definição em oposição ao organicismo delimitado por Ey.

Lacan apresenta a contradição da obra de Ey, ou melhor, o fracasso dessa teoria, a saber: “o limite da neurologia e da psiquiatria (...) Refirome à loucura" (Lacan, 1998, p. 155). Definindo de outra maneira a colocação de Lacan: quem é o paciente neurológico e qual o psiquiátrico na teoria de Henri Ey? Lacan pergunta: "haverá alguma coisa que distinga o alienado dos outros doentes, a não ser pelo fato de o encerrarmos num asilo, enquanto hospitalizamos estes últimos?' (Lacan, 1998, p. 155).

A reflexão de Lacan se dá da seguinte maneira: a loucura é um fenômeno de conhecimento, condição que sempre esteve atrelada às formações delirantes, estabelecendo que "a loucura é vivida no registro do sentido... o fenômeno da loucura não é separável do problema da significação para o ser em geral, isto é, da linguagem para o homem" (Lacan, 1998, p.166). A loucura, na fala de Lacan, é tirada do estatuto de doença e inserida no registro do sentido e da linguagem - nesse momento a linguagem é entendida como "nó de significações" (Lacan, 1998, p. 167) e não como um conjunto de signos ou como significante, entretanto, pode-se compreender como um esboço de sua tese futura - e diz que "o sentido como sentido, que para se descobrir, tem de ser desvelado" (Lacan, 1998, p. 168). Segundo Simanke (2002) "(...) o sujeito pode apreender claramente o sentido de um discurso, mas enquanto ele não se reconhecer nesse discurso, quer como autor, quer como objeto, a sua significação maior permanecer-lhe-á desconhecida".

Para dar um exemplo do que está querendo implantar como forma de conhecimento do louco e da loucura, Lacan utiliza-se do caso Aimée, que permite relacionar desconhecimento e loucura. Ou melhor, demonstrar que o sujeito dá um sentido próprio para o mundo em que vive, um sentido todo particular sem reconhecer que esse sentido é uma interpretação sua da realidade, conhecendo a sua maneira o mundo circundante. Lacan enuncia a capacidade literária de significação subjetiva apresentada pela paciente Aimée nos romances que escrevia e que foi por onde seu médico, após analisá-los, pode constatar a fenomenologia completa da loucura. O diagnóstico da paciente foi investigado por meio das suas "relações com a totalidade dos antecedentes biográficos, das intenções confessas ou não da doente... motivos percebidos ou não, que destacam da situação contemporânea de seu delírio... em suas relações com a personalidade" (Lacan, 1998, p.171). Após elencar os acontecimentos históricos e delirantes da paciente em questão, Lacan aponta 0 evento do desconhecimento como algo observável desde o princípio em sua paciente e acrescenta logo em seguida: "Seguramente, pode-se dizer que o louco se acredita diferente de quem é..." (Lacan, 1998, p. 171). - como Aimée que se acreditava vítima de um complô para lhe tirarem o filho, então, foi preciso acabar com as ameaças que estava recebendo de uma atriz francesa e para tanto atacou tal atriz na entrada de um teatro...

Então, o sujeito desconhece que a sua loucura é uma construção de sentido que faz do mundo, é o sentido que o sujeito dá a seu mundo. Mas o que parece surpreendente nesse momento é que Lacan denuncia que esse desconhecimento que está atrelado à questão da loucura é nada além daquilo que o homem vive na sua constituição como homem, como um eu: "se um homem que se acredita rei é louco, não menos o é um rei que 
se acredita rei" (Lacan, 1998, p. 171). O sujeito não louco, ou melhor, aquele que não é en cerrado num asilo, que não se diagnostica como louco, possui no cerne do seu ser o fenômeno que é característico de uma manifestação da loucura.

Até aqui o que se viu foi a relação entre desconhecimento que está na base da loucura e o sentido que o sujeito dá a esse desconhecimento; e nesse momento para deslindar tal condição, a respeito da loucura e sua convergência à realidade própria do homem, Lacan introduz um novo conceito: a identificação. A loucura não se dá num acidente que ocorre por um mau funcionamento dos neurônios, mas a partir "das identificações que o homem engaja simultaneamente sua verdade e seu ser" (Lacan, 1998, p. 177). Em outras palavras, o que Lacan está tentando trazer a luz é que aquilo que qualifica a loucura num desconhecimento de si mesmo está na origem do homem, aplica-se ao "desenvolvimento dialético do ser humano" (Lacan, 1998, p. 173). O processo identificatório é o momento fecundo do desenvolvimento humano, pois é a partir dele que o infans passa da condição de desconhecimento de si para a possível realização em si da condição humana. Lacan é concludente nesse momento ao dizer que "o ser do homem não apenas não poder ser compreendido sem a loucura, como não seria o ser do homem se não trouxesse em si a loucura como limite da sua liberdade" (Lacan, 1998, p. 177). Nas palavras de Simanke (2002):

\begin{abstract}
Se a loucura é imanente à realidade humana, é porque esta identificação imediata, primária, que está na sua origem, é um momento logicamente necessário na edificação do sujeito e, portanto, os alicerces da subjetividade estão enraizados num solo tipicamente paranóico de identificações perfeitamente constitutivas, das quais o estádio do espelho busca fornecer o modelo (Simanke, 2002, p.239).
\end{abstract}

Lacan fará um percurso para desvelar de onde vêm tais identificações, ou melhor: "apreender a modalidade de forma e de ação que fixa as determinações desse drama (...) identificável com o conceito de imago" (Simanke, 2002, p.179). E, para tanto, Lacan buscará respaldo, a partir do conceito de imago - da sua concepção de estádio do espelho tema que permite compreender a constituição humana nos seus primórdios - para demonstrar como o processo de identificação pro- duz um sujeito, demonstrar a questão do ser e do eu pelo viés da imago, tentando constituir uma ciência nova para dar conta da constituição humana. Lacan define que "a história do sujeito desenvolve-se numa série mais ou menos típica de identificações ideais que representam os mais puros dentre os fenômenos psíquicos por eles revelarem essencialmente a função da imago" (Simanke, 2002, p. 179).

Na psicanálise freudiana, o eu está identificado ao sistema percepto-conscien te reanimado ao mundo pelo princípio de realidade, ou caracterizado por aquele que realiza a síntese. Não, não é nada disso, diz Lacan, é outra coisa. Por um método fenomenológico, nosso autor construiu sua teoria do eu, pelo caminho do conhecimento paranóico, que o levou a um parentesco com a noção de transitivismo que se expressa a princípio como "matriz da Urbild do Eu" a fase mais arcaica do eu e que nunca se elimina da vida do homem por completo. O transitivismo é compreendido como o momento em que, mediante brincadeiras entre duas crianças, pode-se concluir uma "verdadeira captação pela imagem do outro" (Simanke, 2002, p. 182). Ambas estão identificadas, sendo que, quando uma cai, as duas sentem o tombo; uma bate na outra e sente o seu próprio golpe entre outros eventos. Do ciúme até as primeiras manifestações de simpatia, aparecem no espelho lacaniano, na medida em que "o sujeito se identifica, em seu sentimento de si, com a imagem do outro, e que a imagem do outro vem cativar nele esse sentimento" (Simanke, 2002, p.182), o sentimento de si. Esse fenômeno de si misturado ao outro se dá antes de um ano de idade: o acontecimento da alienação ao outro pelo desejo e pelo desconhecimento. Eis aqui o primeiro efeito da imago: "a alienação do sujeito. É no outro que o sujeito se identifica e até se experimenta no princípio" (Simanke, 2002, p. 182). Em seu Seminário 1 - alguns anos à frente desse Congresso, Lacan diz que a forma do outro é assumida, está no seu interior, o "fora do dentro, por meio de que o sujeito se sabe, se conhece como corpo (...) É na troca com o outro que o homem se apreende como corpo; mas não só: também o desejo, é só no outro que ele aprenderá a reconhecê-lo" (Lacan, 1986, p.197).

Lacan refaz uma pequena análise de seu trabalho da fase do espelho para demonstrar as relações imaginárias de uma determinada fase do desenvolvimen to humano. Isto é, a assunção triun- 
fante da criança aos seis meses de idade frente ao espelho levando a uma ação identificatória pela imago, isso acompanhado de mímicas jubilatórias da criança frente a essa novidade que a capta. Essa determinação imaginária acontece na formação humana por ser o homem dotado de um atraso do desenvolvimento do neuro-eixo considerado pelo embriologista um ser prematuro em seu nascimento. Então, como em toda falha da natureza há uma compensação, o que surge no infans é um desenvolvimento acelerado da percepção visual; de um lado um corpo que não pode responder adequadamente e de outro uma estrutura visual avantajada que impõe, à criança, sua entrada no mundo imaginário, formando, como chamado pela psicanálise, seu narcisismo.

Lacan chega onde quer: definir a causalidade psíquica que tem relação com a gênese do eu, ou melhor, com a fase do espelho, que é resultado de uma identificação, perpassando pelo desconhecimento e a alienação constitutivos da realidade humana.

Funda-se uma forma de causalidade que é a própria causalidade psíquica - a identificação, que é um fenômeno irredutível -, e a imago é a forma definível, no complexo espaço-temporal imaginário, que tem por função realizar a identificação resoluta de uma fase psíquica, ou, em outras palavras, uma metamorfose das relações do indivíduo com seu semelhante (Lacan, 1998, p. 189).

A imago torna-se, assim, o tão esperado objeto para uma psicologia científica, tal qual a matéria o é para a física. E aqui onde nos encontramos na trama lacaniana o que possibilita essa fundação, pela causalidade psíquica, é a identificação pelo estatuto mesmo do processo de formação que provém da imago. Lacan observa, por conta da condição humana, a ameaça que caminha lado a lado com homem: "se nada pode garantir que não nos percamos em um movimento livre rumo ao verdadeiro, basta um nadinha para nos assegurar de que transformemos o verdadeiro em loucura" (Lacan, 1986, p.193).

Resumindo o esquema lacaniano. Lacan faz uma crítica do organo-dinamismo de Henri Ey num congresso que tinha como tema a psicogênese. Essa crítica ele a introduz para trazer a sua formulação do que se pode entender por psicogê- nese e que permeia a sua produção teórica como uma tentativa de criar uma psicologia concreta que tenha um objeto respaldado por uma condição de cientificidade. Para isso, Lacan foi do fenômeno da loucura para a formação do eu, demonstrando que o desconhecimento intrínseco da loucura também é condição da constituição da subjetividade. Ou melhor, a condição da alienação ao outro que coloca o infans num desconhecimento de si e, desta forma, identificando-se com essa imago que o captou, constituindo-se como um sujeito. Lacan chega ao conceito de imago que dá substrato ao momento da realização em um bebê pela identificação apontando que, o eu que se crê si mesmo, é um outro, tal qual o louco que crê ser o que não é. Perde-se, nessa produção lacaniana, a linha que separava a normalidade e loucura, deixando esta entrelaçada à vida como mais uma das grandes possibilidades da condição humana. Dessa maneira, não é a loucura um mau funcionamento do corpo que resulta num mental desprovido de razão, mas o exagero da constituição humana, o sentido que se é possível dar ao mundo. Lacan busca com esta explanação sobre a loucura reintroduzir o sujeito nos transtornos mentais, isto é, um sujeito e, conseqüentemente, uma subjetividade.

A loucura, essa tal perda da capacidade racional, em Lacan, não é compreendida pelo viés da falta, da perda, mas pelo excesso. A loucura é entendida como a expressão excessiva daquilo que constitui o homem: a identificação a alguma coisa, tornando-se essa coisa. O louco era entendido a partir dos deuses, destes passou a ser compreendido pela possessão demoníaca, do diabo ao olhar e saber da ciência para sair como o senhor de seu sentido. Sendo assim, é possível afirmar que o louco é uma construção da época em que vive, um ser que hoje é, já não mais com as amarras que Pinel soltou, mas controlado pela vergonha de uma sociedade que não suporta se reconhecer neste lugar dito alienado e, portanto, deve afastar, senão por explicações divinas, diabólicas ou médicas, o homem insano da sua responsabilidade. Lacan transforma essa vertente em responsabilidade, pois o louco é responsável pela sua loucura. Há um sujeito que enlouqueceu e não apenas um fenômeno externo ou uma disfunção metabólica que tirou o homem da sua razão. Há um homem, não por trás da loucura, mas na própria loucura.

Afinal, vivemos, atualmente, num mun- 
do em que os princípios morais e a sua prática andam em lados opostos em nome de uma ideologia individualista que envolve apenas o bem pessoal a todo custo, e, não nos resta muita alternativa gritar, como loucos, pelos poros da vida, um grito, no entanto, silenciado pela evolução farmacológica, pois, é preferível esconder a reconhecer.

Contudo, não adianta travestir o horror que se tem da loucura e do louco com reforma que, supostamente, visam a reabilitar o homem e a sociedade que o esconde sem apresentar soluções suficientemente concretas que estejam de acordo com a condição socioeconômica da população precisada. Senão, é como falar em miséria, sem querer sanar a fome, em educação sem ofertar livros, em saúde, sem leitos à disposição. Fica apenas um discurso sem ação. E, sendo assim, o que devemos esperar, nós homens e loucos, do novo século?

\section{Referências}

Canguilhem, G. (2002). O normal e o patológico. Rio de Janeiro: Forense Universitária.

Lacan, J. (1198). Formulações sobre a causalidade psíquica: in Escritos. Rio de Janeiro: Jorge Zahar.

Canguilhem, G. (2002). Os escritos técnicos de Freud. Seminário 1. Rio de Janeiro: Jorge Zahar, 1986.

Pessotti, Isaias. (1995). A loucura e as épocas. São Paulo: Editora 34.

Simanke, R. T. (2002). Metapsicologia lacaniana, os anos de formação. São Paulo: Discurso; Curitiba: Editora UFPR.

Recebido em/ received in: 26/05/2004 Aprovado em/ approved in: 27/08/2004 